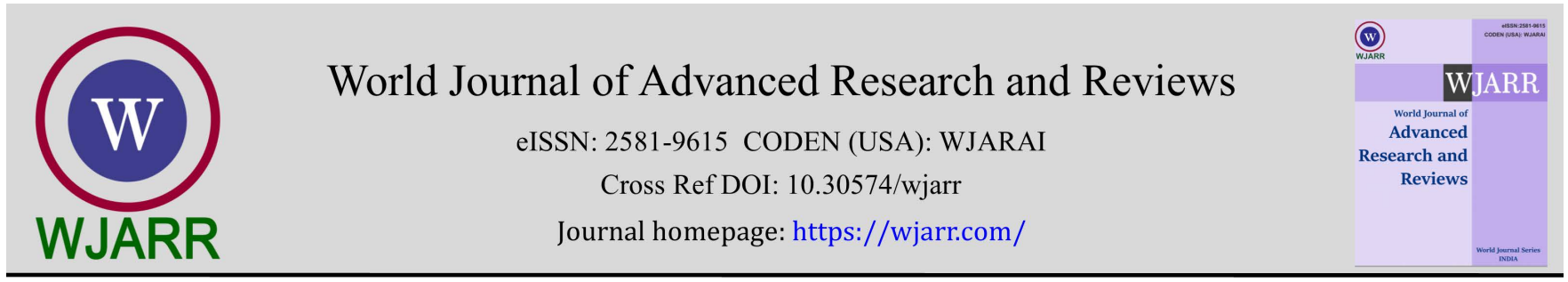

(RESEARCH ARTicle)

Check for updates

\title{
Occupational Therapy Education in Bangladesh during COVID-19: Students' voice
}

\author{
Sk. Moniruzzaman 1, Nayan Kumer Chanda ${ }^{2,}{ }^{*}$, Md. Saddam Hossain ${ }^{3}$, Md. Habibur Rahman ${ }^{4}$, Mohuya Akter 5 , \\ Salma Akter ${ }^{6}$ and Kaniz Fatema ${ }^{7}$ \\ Department of Occupational Therapy, Bangladesh Health Professions Institute (BHPI), Centre for the Rehabilitation of the \\ Paralysed (CRP), Savar, Dhaka, Bangladesh.
}

World Journal of Advanced Research and Reviews, 2021, 12(03), 652-660

Publication history: Received on 23 November 2021; revised on 28 December 2021; accepted on 30 December 2021

Article DOI: https://doi.org/10.30574/wjarr.2021.12.3.0741

\begin{abstract}
The COVID-19 has rapidly changed in higher education all across the world. As a result, education has transferred faceto-face teaching to online education platforms, which directly affects the quality of education. The study aimed to explore the impact of the COVID-19 pandemic on online Occupational Therapy (OT) education in Bangladesh through the student's perspectives.

A cross-sectional online survey was performed to conduct the study through email.160 undergraduate Occupational Therapy students were selected by comprehensive sampling technique. Self-developed structured survey questionnaire and five point Likert scale were used for data collection. Descriptive analyses were used to analyze survey results.

Data were obtained from 114 responses. Results indicated that males were $34 \%$ and females were $66 \%$. The study findings that most participants were used Zoom and mobile phone. They had an average of 10-12 hours weekly screen time for institutional lectures and 3-5 hours average weekly screen time for self-study. The reported health-related problems were eye problem $74.6 \%$, attention problem $71.1 \%$, headache $70.2 \%$ and $57 \%$ neck and back pain. During the online education, 59.6\% participants faced 'always' difficulties in practical learning. 98.2\% faced internet disconnection, $70.2 \%$ and $43 \%$ audio and video interruption and 39.5\% freeze screen during internet use. Participants developed new skills in the pandemic where 78.9\% were learned household activities. Strength of the online education was participants engaged in the class from anywhere.
\end{abstract}

The study has broad implications for the field of OT education. Participants recommended for improving internet connectivity, provide free internet packages, lecture method up-gradation, and e-library facilities for future online education.

Keywords: COVID-19; Occupational Therapy Education; Bangladesh; Online Education

\section{Introduction}

Corona Virus Disease 2019 (COVID-19) is often referred to as novel coronavirus [1]. World Health Organization (WHO) declared this disease a global public health emergency of international concern on 30 January 2020 and a pandemic on 11 March 2020 [2]. In Bangladesh, the first case of COVID-19 was confirmed on 8 March 2020, and till 31 August 2021, the country's total number of cases is $1,500,618$, and the number of deaths is 26,195 deaths. Bangladesh Government instructed to close all its institutions from 17 March 2020. As per the order, all the institutions across the country shut down their campuses and immediately opted for online learning to maintain social distance [3].

\footnotetext{
${ }^{*}$ Corresponding author: Nayan Kumer Chanda

Department of Occupational Therapy, Bangladesh Health Professions Institute (BHPI), Centre for the Rehabilitation of the Paralysed (CRP), Savar, Dhaka, Bangladesh.

Copyright (C) 2021 Author(s) retain the copyright of this article. This article is published under the terms of the Creative Commons Attribution Liscense 4.0.
} 
Nationwide closures due to the COVID-19 outbreak are impacting over $60 \%$ of the world's student population, while millions of additional learners' learning processes have been disrupted due to the localized closure of academic institutions [4]. This devastating pandemic impacted conventional education activities around the globe and compelled academic experts to reconsider the traditional way of face to face learning, and they started considering distance learning as a feasible option [2]. Since using the online platform is needed to achieve learning goals, innovation in learning is crucial to developing the world's education [5]. Lister [6] shows learning structure, content presentation, collaboration \& interaction, and timely feedback as four primary considerations in designing online learning .The current circumstances are unique and different from typical digital learning situations, which could be called crisis learning [7]. Along with the crisis period, the possible learning model is learning through the network systems, such as e-learning [8].

Dhawan [9] stated that e-learning offers many benefits to students because this type of learning nurtures studentcenteredness where students take responsibility for their learning. On the other hand, online learning could be effective in digitally advanced countries [10].

Countries with a lack of resources in academic institutions and the social marginalization of students, where insufficient access and availability of the internet and the lack of latest technology affect organizational responsiveness and students' capacity to participate in digital learning [11]. A few research studies have shown the challenges and opportunities associated with e-learning during pandemics from the perspective of various stakeholders [12]. Thus, the researchers explore the strength and challenges of recent online learning initiatives from students' opinions. Since students are experiencing challenges that hinder them from achieving learning goals, their voices are essential on this issue.

Adnan and Anwar [2] also suggested conducting a study about the challenges and opportunities of online learning from students' points of view. Furthermore, researchers seem the way to overcome challenges and utilize online learning opportunities should be investigated in future studies.

The Bangladesh Health Professions Institute (BHPI) was established in 1992 to develop highly skilled multidisciplinary health care professionals. It is the academic institute of the Centre for the Rehabilitation of the Paralysed (CRP). BHPI is running three Occupational Therapy courses in Bangladesh. These are Bachelor of Science in Occupational Therapy, Diploma in Medical Technology (Occupational Therapy) and Occupational Therapy Assistant course. BHPI is the only Occupational Therapy academic institute in Bangladesh.

Total undergraduate B.Sc. in Occupational Therapy students are 160 . The course duration is five years (4 years academic \& 1-year internship) [13].During COVID-19, most students are unable to access the internet due to technical and monetary issues. The lack of face-to-face communication with the educators, response time and absence of traditional classroom socialization were among some other issues highlighted by higher education students [2]. Most teachers are just conducting lectures on video platforms such as Zoom, WhatsApp (WA) account, and Google meets etc., which may not be real online learning without any dedicated online learning platform [14].

In this study, investigators aim was to find out the changes in Occupational Therapy undergraduate education in Bangladesh during COVID-19 pandemic situation. As a result, the investigator would be able to know and overcome the students' challenges faced during COVID-19 pandemic. On the other hand, educators knew how learning strategies have been changed in the pre and during COVID-19 situation. It would be easy to know the adopted learning strength of the undergraduate Occupational Therapy students of Bangladesh Health Professions Institute. By this study, investigators knew the students' participation in the online classes during this situation and to know whether their up skills are developing.

\section{Material and methods}

A cross-sectional descriptive study design was selected to identify the changes in Occupational Therapy undergraduate education in Bangladesh during the COVID-19 pandemic. The design included a cross-sectional survey consisting of quantitative responses to know the student's difficulties and health-related problems during online education, new skills, strength and their recommendation.

\subsection{Sampling}

The sample consisted of undergraduate B.Sc. in Occupational Therapy students from Bangladesh Health Professions Institute (BHPI), CRP across Bangladesh, who meet the inclusion and exclusion criteria. The Inclusion criteria were 
Participants who were attending the online class and took supervision during the COVID-19 situation. Exclusion criteria were those who did not attend the online classes. One hundred fourteen undergraduate Occupational Therapy students were selected by comprehensive sampling technique through an email invitation asking for survey participation.

\subsection{Instrumentation}

Researchers used self-developed structure survey questioners to collect the data to determine the changes in Occupational Therapy undergraduate education in Bangladesh during the Covid-19 pandemic. 5 point Likert scale questioner also used to know the difficulties of the participant during online education. The data collection was facilitated through an online survey through Microsoft Google Form. The researchers did a pilot test of the instrument, and experts reviewed the instrument to justify the reliability and validity of the questioner fit with the Bangladesh context.

\subsection{Procedure}

Researchers had approval from the Institutional Review Board (IRB) of Bangladesh Health Professions Institute, Centre for the Rehabilitation of the Paralysed (CRP). All participants had given concern to participate in this study.

To reduce the power relation bias, the questioners were disseminated through the other person who has no direct academic relationship with the participants. So, researchers recruited a volunteer. He collected all students email addresses for data collection and sent the questioners through email for a fill-up by collecting all data volunteer submitted to the research team.

\subsection{Data Analysis}

The online questioner was sent to the 160 participants. Out of 160 participants, 114 participants had given their responses through email. Forty-six participants did not give response online. So, researchers had gotten 114 data for data analysis.

Statistical analysis was performed using SPSS (Statistical Package for Social Science) software version 22 to analyze the data. Descriptive analysis was done to know the frequency and percentage of the participants.

On the other hand, multiple response analysis also created a frequency and cross tabulation table for participants' multiple responses. The researcher used the five-point Likert scale to find out the difficulties of the participant during online education. The findings were represented by graphs (bar chart), tables. On the other hand, all multiple results were shown in the percentage of cases.

\section{Results}

Table 1 Socio-demographic characteristics of the participants

\begin{tabular}{|l|l|l|}
\hline Socio-demographic characteristics & Frequency (N=114) & Percentage (\%) \\
\hline Gender of the participants & 39 & $34 \%$ \\
\hline Male & 75 & $66 \%$ \\
\hline Female & \multicolumn{2}{|l|}{} \\
\hline Age (year) & 114 & $100 \%$ \\
\hline $18-24$ & 29 & $26 \%$ \\
\hline Years of the Students & 30 & $26 \%$ \\
\hline $1^{\text {st Year }}$ & 33 & $29 \%$ \\
\hline $2^{\text {nd Year }}$ & 22 & $19 \%$ \\
\hline $3^{\text {rd Year }}$ & \multicolumn{2}{|l|}{} \\
\hline $4^{\text {th Year }}$ & 24 & $21 \%$ \\
\hline Living area during Covid-19 & 40 & $35 \%$ \\
\hline Rural & 50 & $44 \%$ \\
\hline Semi-urban &
\end{tabular}


The study was conducted with 114 participants. Table 1 shows that males were 34 (39) and females were 66\% (75) among the participants. The study participants in different years of student among them $26 \%$ (29) participants were 1st year, 26\% (30) participants were 2nd year, 29\% (33) participants were 3rd year, and 19\% (22) participants were 4th-year students. The participants living areas were 44\% (50) urban, 35\% (40) semi-urban, and 21\% (24) rural during the Covid-19 situation.

Figure 1 shows that all participants used zoom for study purposes with educators. 100.0\% (114) participants used to zoom, 77.2\% (88) participants used Facebook messenger, 78.1\% (89) participants used WhatsApp, 53.5\% (61) participants used email, and $37.7 \%$ (43) participants used audio calls for study purposes with educators.

Among the participants, they said Facebook messenger was a common medium for study purposes with peer groups. Total 86.8\% (99) participants used Facebook messenger, 77.2\% (88) participants used to zoom, 84.2\% (96) participants used WhatsApp, 44.7\% (51) participants used email, and 41.2\% (47) participants used audio calls for study purpose with the peer.

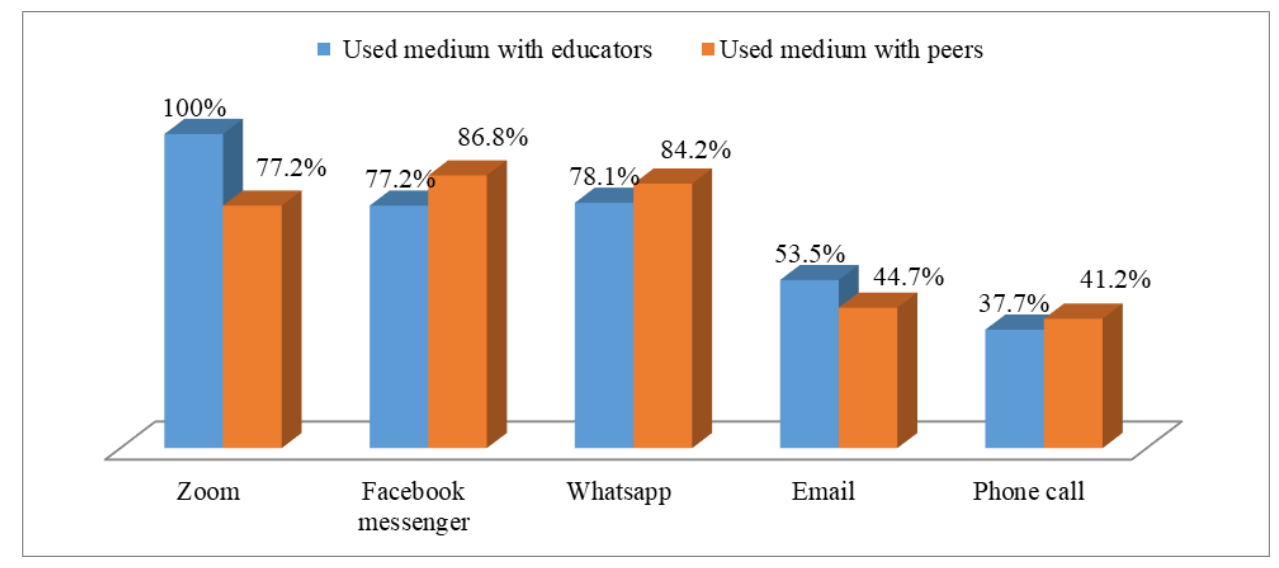

Figure 1 Medium of study with educators and peers

Figure 2 shows that most of the participants, $100.0 \%$ (114), used mobile phones for study purposes whereas $34.2 \%$ (39) used laptops, 12.3\% (14) used a tablet and only 5.3\% (6) used computer

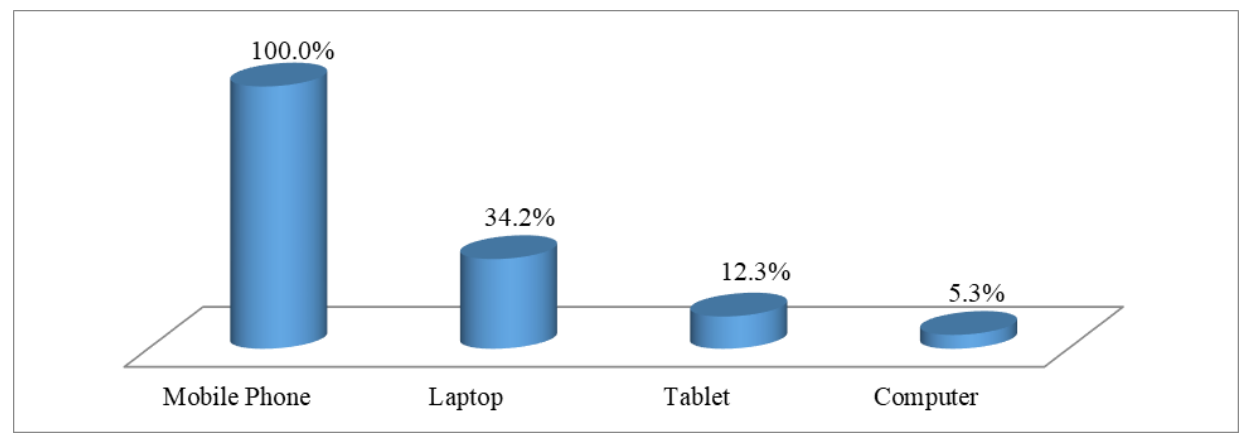

Figure 2 Device for study purpose

Figure 3 shows that 65 participants said they had an average of 10-12 hours of weekly screen time, and 49 participants responded that they had 7-9 hours weekly for the intuitional lecture. On the other hand, 70 participants said they had an average of 3-5 hours of weekly screen time, and 44 participants responded that they had 6-8 hours weekly for selfstudy.

Table 2 shows that $74.6 \%$ of participants responded that they had an eye problem, and $10.5 \%$ responded that they had no health-related problems out of 114 participants. Other problems were poor attention/concentration, headache, neck pain, back pain, irritation, slowed learning, drowsiness, anxiousness and aggressiveness. 


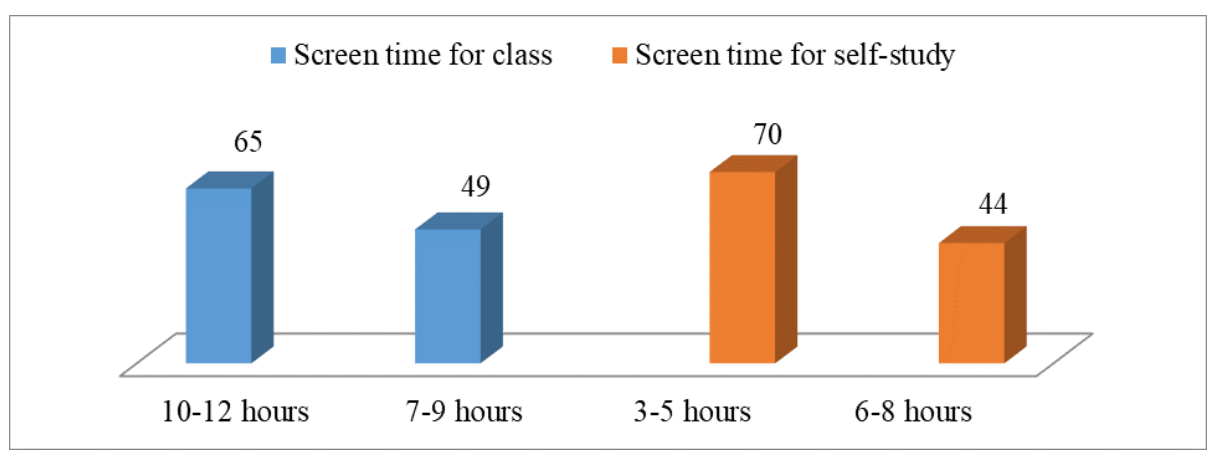

Figure 3 Average weekly screen time of student

Table 2 Health related problems of the participants

\begin{tabular}{|l|l|}
\hline Health related problems & N (\%) \\
\hline Eye problem & $85(74.6)$ \\
\hline Poor attention/concentration & $81(71.1)$ \\
\hline Headache & $80(70.2)$ \\
\hline MSS (Neck pain, back pain, Muscle ache) & $65(57.0)$ \\
\hline Irritation & $47(41.2)$ \\
\hline Slowed learning & $42(36.8)$ \\
\hline Drowsiness & $31(27.2)$ \\
\hline Anxiousness & $24(21.1)$ \\
\hline Aggressiveness & $16(14.0)$ \\
\hline Not applicable & $12(10.5)$ \\
\hline
\end{tabular}

Table 3 Difficulties of online education

\begin{tabular}{|c|c|c|c|c|c|}
\hline Variables & Always & Often & Sometimes & Rarely & Never \\
\hline $\begin{array}{l}\text { How much difficulty are you facing } \\
\text { in understanding lectures? }\end{array}$ & $9(7.9 \%)$ & $30(26.3 \%)$ & 66 (57.9\%) & $8(7 \%)$ & $1(.9 \%)$ \\
\hline $\begin{array}{l}\text { How much difficulty are you facing } \\
\text { in Class-based individual tasks? }\end{array}$ & $5(4.4 \%)$ & $26(22.8 \%)$ & $69(60.5 \%)$ & $12(10.5 \%)$ & $2(1.8 \%)$ \\
\hline $\begin{array}{l}\text { How much difficulty are you facing } \\
\text { in group work? }\end{array}$ & $24(21.1 \%)$ & 32 (28.1\%) & 45 (39.5\%) & $12(10.5 \%)$ & $1(.9 \%)$ \\
\hline $\begin{array}{l}\text { How much difficulty are you facing } \\
\text { in Practical learning? }\end{array}$ & $68(59.6 \%)$ & $24(21.1 \%)$ & $22(19.3 \%)$ & & \\
\hline $\begin{array}{l}\text { How much difficulty are you facing } \\
\text { in active participation? }\end{array}$ & $18(15.8 \%)$ & $26(22.8 \%)$ & $59(51.8 \%)$ & $9(7.9 \%)$ & $2(1.8 \%)$ \\
\hline $\begin{array}{l}\text { How much difficulty are you facing } \\
\text { in coursework? }\end{array}$ & $16(14 \%)$ & 25 (21.9\%) & $59(51.8 \%)$ & $7(6.1 \%)$ & $7(6.1 \%)$ \\
\hline $\begin{array}{l}\text { How much difficulty are you facing } \\
\text { in class test? }\end{array}$ & $11(9.6 \%)$ & 27 (23.7\%) & $55(48.2 \%)$ & 13 (11.4\%) & $8(7 \%)$ \\
\hline $\begin{array}{l}\text { How much difficulty are you facing } \\
\text { in homework? }\end{array}$ & $2(1.8 \%)$ & 17 (14.9\%) & $52(45.6 \%)$ & $29(25.4 \%)$ & $14(12.3 \%)$ \\
\hline $\begin{array}{l}\text { How much trouble are you facing in } \\
\text { internet use regarding academic } \\
\text { activities? }\end{array}$ & $20(17.6 \%)$ & $29(25.4 \%)$ & 57 (50\%) & $8(7 \%)$ & \\
\hline
\end{tabular}


Table 3 demonstrated the difficulties of the participants during online education that showed in percentage. During online education, some difficulties were understanding lectures, group work, class tests, practical learning, coursework, active participation, internet use regarding academic activities, etc.

During the internet use $98.2 \%$ (112) participants responded that they face internet disconnection, 70.2\% (80) audio interruption, $43.0 \%$ (49) video interruption, 39.5\% (45) freeze screen and 38.6\% (44) screen sharing. (See figure: 4 )

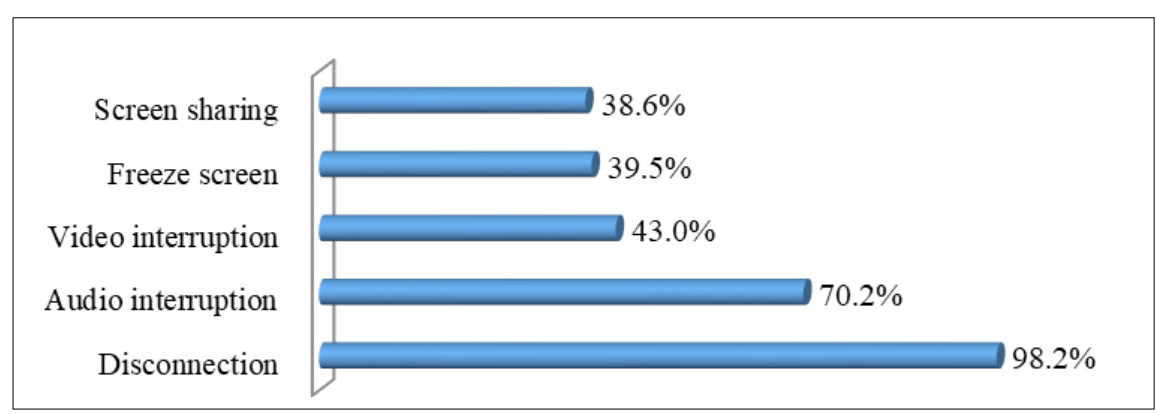

Figure 4 Participants faced difficulties during internet use

During the pandemic period, all participants were developed new skills. Among them, 78.9\% of participants responded that they learned household activities, $66.7 \%$ leisure activities, 37.7\% e-learning, 32.5\% video editing, $24.6 \%$ leadership, $22.8 \%$ data management \&volunteer support, $21.1 \%$ online businesses, $15.8 \%$ computer literacy, $7 \%$ graphic design and 5.3\% software development. (See table 4)

Table 4 New skills were developed during apart from academic needs

\begin{tabular}{|l|c|}
\hline New skills & N (\%) \\
\hline Household activity & $90(78.9)$ \\
\hline Leisure activity (gardening, sports, singing, drawing, mobile photography, paper crafts etc) & $76(66.7)$ \\
\hline E-learning & $43(37.7)$ \\
\hline Video editing & $37(32.5)$ \\
\hline Leadership development & $28(24.6)$ \\
\hline Data management & $26(22.8)$ \\
\hline Volunteer support & $26(22.8)$ \\
\hline Online business & $24(21.1)$ \\
\hline Computer literacy & $18(15.8)$ \\
\hline Graphics design & $8(7.0)$ \\
\hline Software development & $6(5.3)$ \\
\hline No develop any new skills & $0(0)$ \\
\hline
\end{tabular}

Table 5 Strengths of online education

\begin{tabular}{|l|l|}
\hline Strengths of online education & N (\%) \\
\hline Participated in education from anywhere & $90(78.9)$ \\
\hline New technology use for education & $85(74.6)$ \\
\hline Online presentation skills & $82(71.9)$ \\
\hline Continued education in the pandemic & $81(71.1)$ \\
\hline Device (mobile, laptop, computer etc.) management skills & $75(65.8)$ \\
\hline Coping skills in new learning system & $61(53.5)$ \\
\hline
\end{tabular}




\begin{tabular}{|l|l|}
\hline Developed strong family bonding & $49(43.0)$ \\
\hline Application (apps, software etc.) management & $49(43.0)$ \\
\hline
\end{tabular}

Table 5 demonstrated the strength of online learning among the participants $78.9 \%$ were participated in online education from anywhere, $74.6 \%$ coping with new technology and others online learning strengths were online presentation skills, continued education, device management skills, coping skills in the new learning system, strong family bonding and application management.

\section{Discussion}

The study result found that $66 \%$ of participants were female and $34 \%$ male. Another study in Nepal showed that $50.5 \%$ of participants were male, and $49.4 \%$ were female out of 89 participants [15]. In this study, the participants, 44\%, lived in the urban, $35 \%$ semi-urban and $21 \%$ rural area during COVID-19. The current study shows that $64.7 \%$ of participants live in urban and $35.3 \%$ in rural [16].

In this study, $100.0 \%$ of participants used the zoom medium, 78.1\% WhatsApp, 72.2\% Facebook Messenger, 53.5\% email, and $37.7 \%$ used phone calls for study purposes with educators, whereas $86.8 \%$ of participants use Facebook messenger, $84.2 \%$ WhatsApp, $72.2 \%$ zoom, $44.7 \%$ email, $41.2 \%$ used audio call for study purpose with the peer group.

An interesting view was expressed by Wargadinata [5] that $48.9 \%$ of participants said that WhatsApp was the very effective medium, $23.4 \%$ e-learning and $14.9 \%$ participants said zoom was the effective medium for online learning out of 225 respondents. Adnan [2] found that $71.4 \%$ of students felt that they used the computer/laptop for online learning purposes. In another study in China, $71.3 \%$ of students used a mobile phone for online learning [17].

A recent qualitative study concluded that some participants had no electronic devices such as computers, laptops, smartphones, or tablets to take part in online classes [18]. This study found, $100.0 \%$ of students used mobile phones, $34.2 \%$ laptops, $12.3 \%$ and $5.3 \%$ of participants used the computer for study purposes. $68.4 \%$ of participants responded that they had their own devices out of 114 participants, and 38.6\% responded that they borrowed any device from others during the online study.

In our study, 65 participants said they had an average of 10-12 hours of weekly screen time, and 49 participants had 79 hours weekly for the intuitional lecture. On the other hand, 70 participants said they had an average of 3-5 hours of weekly screen time, and 44 participants had 6-8 hours weekly for self-study. The current study said that one-quarter of students increased their study time by more than 4 hours per week due to COVID-19, while another quarter decreased their study time by more than 5 hours per week out of 1500 participants[19].

This investigation found that the majority of participants were suffering health-related problems where $74.6 \%$ had eye problems, $71.1 \%$ poor attention, $70.2 \%$ headache, $57.0 \%$ musculoskeletal syndrome (neck \& back pain, muscle ache), $41.2 \%$ irritation, $36.8 \%$ slowed learning, $27.2 \%$ drowsiness, $21.1 \%$ anxiousness, $14.0 \%$ aggressiveness on the contrary $10.5 \%$ participants responded not applicable.

In Nepal, a study found that during the online education, the participants were suffered health-related problems among them back pain $35.1 \%$, neck pain $25.7 \%$, eye pain $55.4 \%$, headache $39.2 \%$, cannot sleep properly $13.5 \%$, anxiety $27 \%$ out of 74 participants [20].

This study revealed that $59.6 \%$ of participants face difficulties "always" in practical learning whereas $21.1 \%$ in group work and $17.6 \%$ in internet using. $60.5 \%$ of participants responded that they faced difficulties "sometimes" for the individual class-based task as $57.9 \%$ in understanding lecture and $51.8 \%$ in active participation, course work. In homework, $12.3 \%$ of participants said they "never" faced difficulties and $7 \%$ in-class tests.

In the another study it is found that participants' difficulty of understanding practical-work based or lab-based content during online classes.42.9\% of students felt problem to do their group projects or assignments through online education, and $34.1 \%$ of students felt that group projects and assignments completion is possible through digital learning. 
This study presents that $98.2 \%$ of participants faced internet disconnection during internet use for an online class, whereas $70.2 \%$ of participants reported audio interruption and $43.0 \%$ expressed video interruptions. Some participants had no access to the internet at their homes while some experienced low or no speed or frequent power cut problems during internet use [18]. According to their study, a total of $86.5 \%$ of students reported limited internet access, whereas $51.6 \%$ mentioned signal unavailability as a reason behind this limited internet access. In another study conducted in South Asia-Nepal found that online classes remain ineffective due to poor internet connectivity, which is complained about by $79 \%$ of the [15]. In this research, participants reported that they developed new skills in this pandemic situation.

This study showed that 90 participants responded that they engaged in household activities, 76 participants were involved in leisure activities, 43 participants occupied e-learning and 26 attracted data management \& volunteer support.

During the lockdown, most of the participants spent their time for household and leisure activities like cooking, farming, gardening, handcrafts, videos on YouTube, reading stories or holy books and doing social work or religious activities [18].

This study expressed that $74.6 \%$ of participants were coping with new technology use for online education, $71.9 \%$ of participants thought that online learning improved their online skills. A current study in India revealed that the pandemic situation induced students to learn and use digital technology and increased digital literacy. $71.1 \%$ of participants stated that they did continue their online learning activities [21].

In this study, the researcher wants to know the participants' recommendations for improving the further online education system that's why participants were recommended to improve the internet connectivity, online-based lecture methods up-gradation, data package support from the institute, short duration of classes, recording the class and elibrary facilities at Occupational Therapy Department, Bangladesh Health Professions Institute (BHPI) in Bangladesh.

\section{Limitation}

The current study faced some limitations in conducting the research. These were online surveys during this pandemic (COVID-19) situation. The researcher found limited literature on online education. In this study sample size were small.

\section{Conclusion}

Online education changed the education system during the COVID-19 pandemic situation in Bangladesh. Students joined their classes by the online platform in pandemic situation and faced different difficulties. On the other hand, they were more benefited from online education. Online education needs good internet connectivity, online-based lecture notes up-gradation, digital literacy training to the current faculty, data package support from the institution, and good elibrary facilities. The finding will assist in improving the future online education system.

\section{Compliance with ethical standards}

\section{Acknowledgments}

The authors acknowledge all the study participants for their time and cooperation. Special thanks to the respective authorities for their permission to conduct the study within the scheduled time. On the other hand, thank you so much Md. Saleh Ur Rahman to collect data for reducing the power relation bias.

\section{Disclosure of conflict of interest}

The authors declare no potential conflicts of interest.

\section{Funding}

The authors received no grant for the research, authorship, and or publication of this research. 


\section{Statement of informed consent}

Informed individual consent was taken from all participants included in this study. Ensured that all participant's information maintained confidentiality. Participation was voluntary.

\section{References}

[1] Toquero C. Challenges and Opportunities for Higher Education amid the COVID-19 Pandemic: The Philippine Context. Pedagogical Research. 2020; 5(4): 1-5.

[2] Adnan M, Anwar K. Online Learning amid the COVID-19 Pandemic: Students' Perspectives. Journal of Pedagogical Sociology and Psychology. 2020; 2(1): 45-51.

[3] WHO Bangladesh COVID-19 Situation Reports. First case of COVID-19 in Bangladesh. 2020.

[4] UNESCO. Global Monitoring of School Closures caused by COVID-19. 2020.

[5] Wargadinata W, Maimunah I, Dewi E, Rofiq Z. Student's Responses on Learning in the Early CoVID-19 Pandemic. Tadris: JurnalKeguruandanIlmuTarbiyah. 2020; 5(1): 141-153.

[6] Lister M. Trends in the Design of E-Learning and Online Learning. MERLOT Journal of Online Learning and Teaching. 2014; 10(4): 1-11.

[7] Pace C, Pettit SK, Barker KS. Best Practices in Middle Level Quaranteaching: Strategies, Tips and Resources amidst COVID-19. Becoming: Journal of the Georgia Association for Middle Level Education. 2020; 31(1): 1-13.

[8] Sintema EJ. Effect of COVID-19 on the Performance of Grade 12 Students: Implications for STEM Education. Eurasia Journal of Mathematics, Science and Technology Education. 2020; 16(7): 1-6.

[9] Dhawan S. Online Learning: A Panacea in the Time of COVID-19 Crisis. Journal of Educational Technology Systems. 2020; 49(1): 5-22.

[10] Basilaia G, Kvavadze D. Transition to Online Education in Schools during a SARS-CoV-2 Coronavirus (COVID-19) Pandemic in Georgia. Pedagogical Research. 2020; 5(4): 1-9.

[11] Zhong R. The coronavirus exposes education's digital divide. 17 March 2020.

[12] Mailizar, Almanthari A, Maulina S, Bruce S. Secondary School Mathematics Teachers' Views on E-learning Implementation Barriers during the Covid-19 Pandemic: The Case of Indonesia. Eurasia Journal of Mathematics, Science and Technology Education. 2020; 16(7): 1-9.

[13] Bangladesh Health Professions Institute [Internet].The academic Institute of CRP, Savar ,Dhaka.

[14] Jena PK. Impact of Covid-19 on higher education in India. International Journal of Advanced Education and Research (IJAER). 2020; 5(3): 77-81.

[15] Gautam DK, Gautam PK. Transition to online higher education during COVID-19 pandemic: turmoil and way forward to developing country of South Asia-Nepal. Journal of Research in Innovative Teaching \& Learning. 2021; 14(1): 93-111.

[16] Muflih S, Abuhammad S, Karasneh R, Al-Azzam S, Alzoubi K, Muflih M. Online Education for Undergraduate Health Professional Education during the COVID-19 Pandemic: Attitudes, Barriers, and Ethical Issues. 2020.

[17] Chen T, Peng L, Yin X, Rong J, Yang J, Cong G. Analysis of User Satisfaction with Online Education Platforms in China during the COVID-19 Pandemic. Healthcare. 2020; 8(3): 200.

[18] Dutta S, Smita M. The Impact of COVID-19 Pandemic on Tertiary Education in Bangladesh: Students' Perspectives. Open Journal Of Social Sciences. 2020; 8(9): 53-68.

[19] Aucejo EM, French J, Araya MPU, Zafar B. The impact of COVID-19 on student experiences and expectations: Evidence from a survey. Journal of Public Economics. 2020; 191: 104271.

[20] Dangal M. Health Problems Experienced in Online Learning during COVID-19 in Nepali Universities. International Journal of Online Graduate Education. 2021; 4(1).

[21] Jena PK. Impact of Pandemic COVID-19 on Education in India. International Journal of Current Research. 2020; 12(7): 12582-12586. 